\title{
Seam weld shell element model for thin walled structure FE fatigue design
}

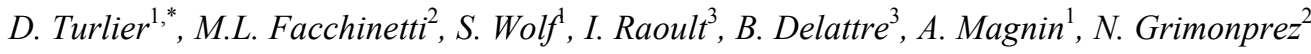 \\ ${ }^{1}$ LOHR Industrie, Duppigheim, France \\ ${ }^{2}$ PSA Groupe, Voujeaucourt, France \\ ${ }^{3}$ PSA Groupe, Vélizy Villacoublay, France
}

\begin{abstract}
In automotive industry, the FE fatigue analysis of mechanical structures made of steel thin walled parts and seam welded assemblies uses a dedicated technique based on shell element modelling for components and on 1D rigid elements for welds. This method has been validated with several intensive fatigue test campaigns using gas metal arc welded samples with different assemblies, for both bending and torsional loads. The fatigue results are relative to crack initiation at the weld toe with bending normal stress or with longitudinal shear stress for several load ratios. The purpose of the current work is the transposition of the initial method to another FE welded model. In a recent IIW guideline for the assessment of weld root fatigue, a shell element weld model has been proposed for seam weld fatigue assessment in case of weld root crack initiation. The idea is to analyse the possible extension of this FEA weld element model for weld toe fatigue analysis and several comparisons of stress results are detailed and discussed. Different fatigue criteria are used to verify the correlation with the fatigue test results. First, the approach is based on maximum shear stress, then structural stress is calculated and results are compared to IIW S/N curves.
\end{abstract}

\section{Introduction}

In automotive industry, the FE fatigue analysis of mechanical structures made of steel thin walled parts and seam welded assemblies uses a dedicated technique based on shell element modelling for components and on $1 \mathrm{D}$ rigid elements for welds $[1,2]$. The stress tensor components are calculated at the weld toe location and the fatigue assessment is performed using a Dang Van maximum shear criterion. This method has been validated with several intensive fatigue test campaigns using gas metal arc welded samples with different assemblies, for both tensile, bending and torsional loads. The fatigue results are relative to crack initiation at the weld toe with bending normal stress or with longitudinal shear stress for several load ratios. The reports of those test campaigns contain all accurate details useful for a numerical correlation. The purpose of the current work is the transposition of the initial method to another FE welded model. In a recent IIW guideline for the assessment of weld root fatigue [3], a shell element weld model has been proposed for seam weld fatigue assessment in case of weld root crack initiation. The weld element model has been validated mainly for asymmetric fillet $\mathrm{T}$ joint weld assemblies $[4,5]$. This kind of assemblies are widely used in industry. An inclined shell element row represents the seam weld with element nodes located at the mid-height of the weld legs.
Weld elements are connected to the metal parts with a series of $1 \mathrm{D}$ rigid and MPC elements combination. The weld leg imprints on the metal sheet allow to define the leg contour. The idea is to analyse the possible extension of this FEA weld element model for weld toe fatigue analysis.

\section{Weld FE Models}

The models for the weld assembly use either Fayard's model which involves $1 \mathrm{D}$ rigid connections $[2,3]$, called "model 1" in the sequel, or the Seamsim method [4] for which the fillet weld is modelled using shell elements over the weld throat mid-height ribbon surface, named "model 2. Thin sheet structures are modelled using shell elements over their mid-surfaces.

\section{1 model 1}

PSA Group currently uses this method for weld seam representation. It involves a specific meshing rule and rigid links between welded steel sheets, as showed in the following figure (Fig.1). 


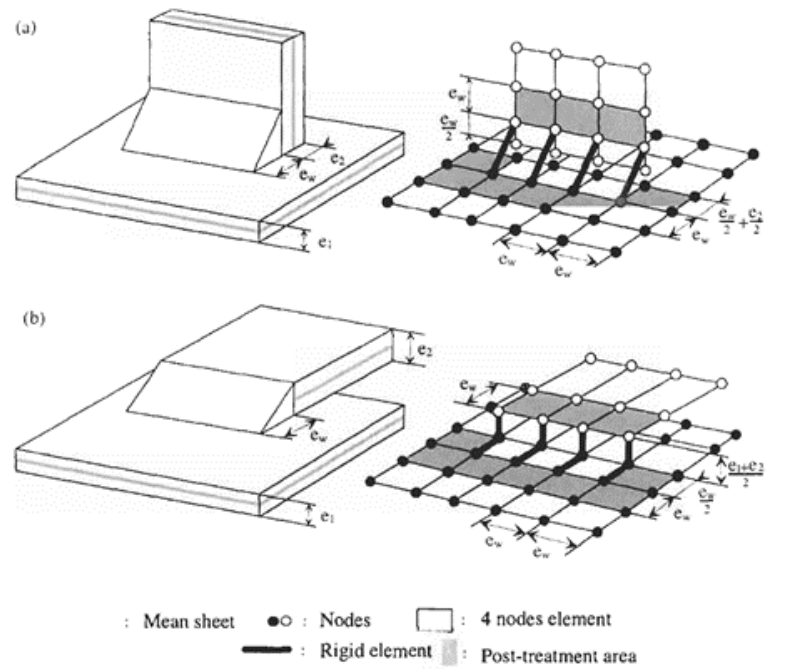

Fig. 1. Fayard model. (a) T-joint, (b) overlap joint.

For fatigue assessment, the stress tensor components are extracted from the centroid of the elements adjacent to the seam weld. The amplitude of the mesoscopic resolved shear stress $\tau_{a}$ is considered in combination with the maximum hydrostatic stress $P$,

$$
\tau_{e q}=\tau_{a}+\alpha P
$$

where $\alpha$ is a material parameter equal to 0.33 , and the resulting equivalent stress is compared to the fatigue limit.

\subsection{Model 2}

Volvo car company did propose a different approach to model the weld seam connection by using a direct shell element connection at the assembly plates weld toe locations $[6,7]$.

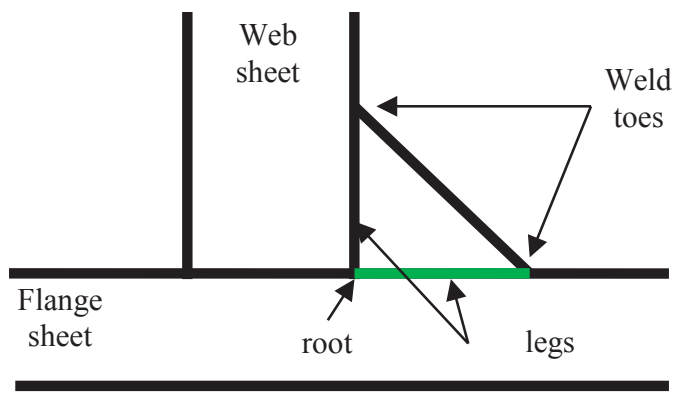

Fig. 2. Weld T joint.

The structural stress calculation is performed based on shell element nodal forces extraction. This technique reduces the dependency to the mesh size and the element quality. The technique has been enhanced by using a shell element row with connections at the weld leg midheight location in order to extend the structural stress analysis for the weld root fatigue assessment $[4,5]$. In order to explain the model, $\mathrm{T}$ joint assembly example is used (Fig. 2).

The assembly is composed of two steel sheets called web and flange, which are linked by a weld seam. First, metal sheet neutral fibres are extracted within the steel sheets and also the weld seam. The weld leg contours are projected over the steel sheet neutral fibre surfaces in order to delimit the weld toe contour (Fig.3).

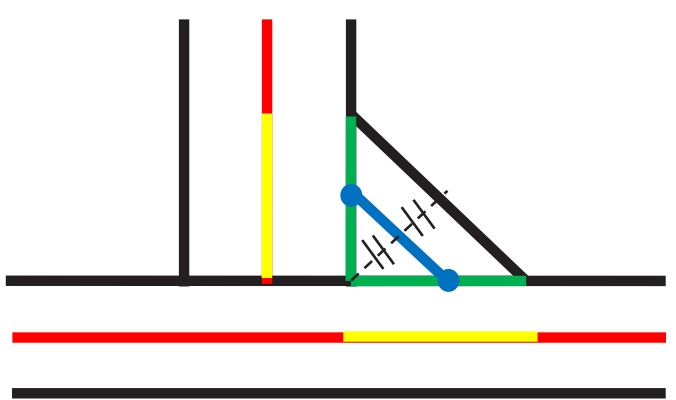

Fig. 3. Model preparation.

Neutral fibre surfaces are meshed using shell elements and the weld connection is performed by using both 1D rigid elements in red colour in Fig.4 and MPC - Multi Point Constraint connections in cyan colour.

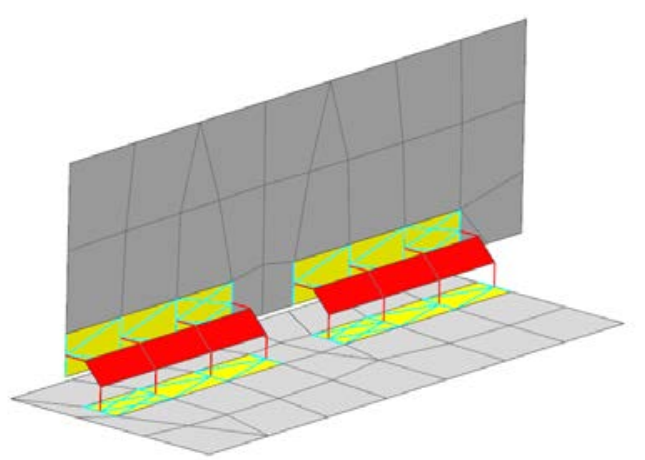

Fig. 4. Assembly model.

For fatigue assessment, at the weld toe, the structural stress approach is used as defined in [8] with shell elements. The structural stress is derived from the through thickness linear gradient stress value at the weld toe. It takes into account the assembly effect but it excludes the weld toe local singularity. As mentioned in [8], stress is calculated based on nodal force and moment extraction.

The fatigue structural stress amplitude is compared to a fatigue limit value.

\section{Fatigue specimens and stress analysis}

\subsection{Specimens description}

According to [1], the specimens have been tested with different loading conditions. They are structures made of mild steel sheets $\left(\sigma_{y}=170 \mathrm{MPa}\right)$ and they are presented in Fig. 5. Residual stresses due to the process have been relieved by a thermal treatment. Specimen D only is made of high strength steel $\left(\sigma_{y}=450 \mathrm{MPa}\right)$ and in this 
case two configurations have been tested, with the residual stresses either relieved or not.

- Specimen A is a double fillet weld $\mathrm{T}$ joint of a simple square plate $5 \mathrm{~mm}$ thick welded onto a $2 \mathrm{~mm}$ thin steel plate.

- Specimen B is a single side fillet weld joint of a $U$ shape folded $3 \mathrm{~mm}$ thick steel sheet welded onto a $2 \mathrm{~mm}$ thick steel plate.

- Specimen C is a traversing "Tube" $3.5 \mathrm{~mm}$ thick and $39 \mathrm{~mm}$ extern diameter welded onto a $2 \mathrm{~mm}$ thick steel plate with a single side fillet welded joint.

- Specimen D is a U shape folded sheet $5 \mathrm{~mm}$ thick welded onto a $2.5 \mathrm{~mm}$ thick and $50 \mathrm{~mm}$ extern diameter tube.

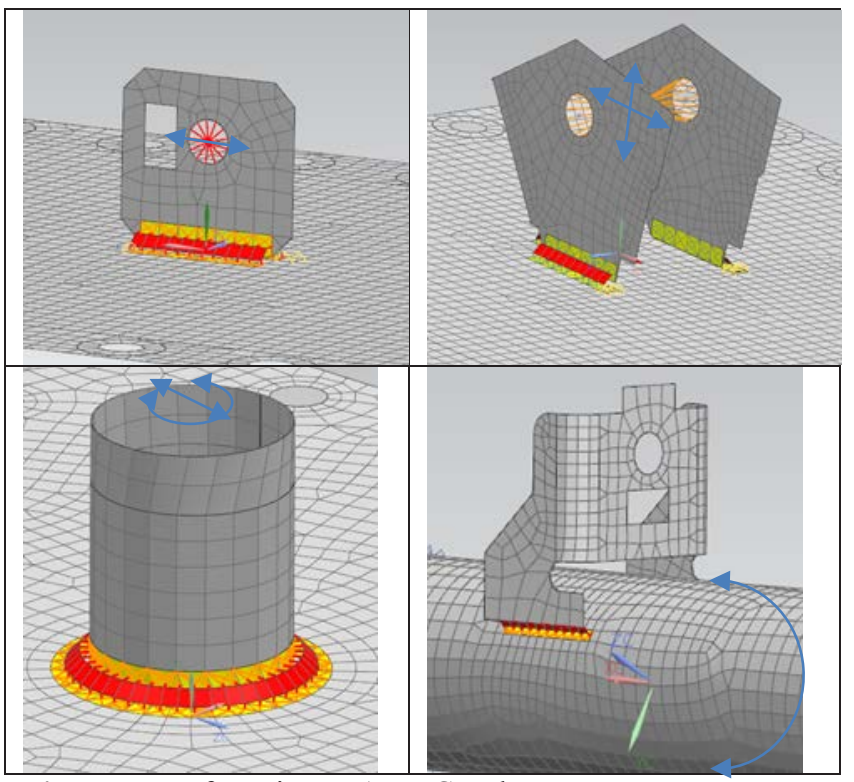

Fig. 5. FEM of specimens A, B, C and D.

Under a constant amplitude cyclic load, the failure criterion is expressed by the cycle number $\mathrm{N}$ corresponding to a significant increase in the crack growth rate, moreover correlated to a $30 \%$ decrease of the signal of a strain gauge located at a distance of $3 \mathrm{~mm}$ from the hot-spot.

\subsection{Load and boundary conditions}

In each case (except for specimen D), the support steel sheet is clamped on its edges by a series of screws.

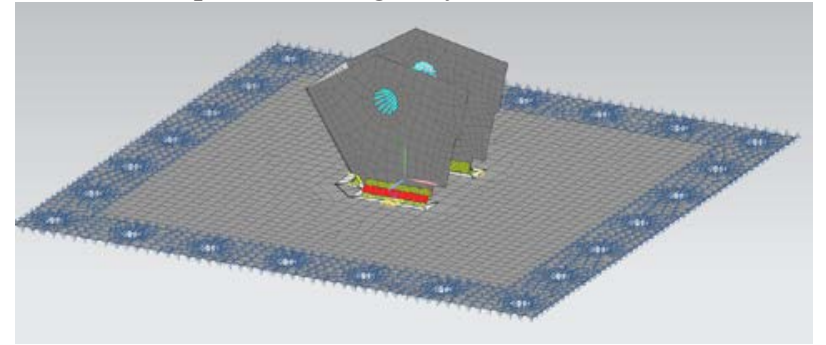

Fig. 6. Specimen B constrain conditions.

In the case of specimen D, a fixed constraint has been applied on a side of the support tube (left side of the picture D, Fig.5.) and bending loads are applied on the tube's other side so that the applied force is orthogonal to the tube and in the direction of the drilled hole folded plate face.

\subsection{Loading conditions}

In specimen $\mathrm{A}$, the load is applied through rigid connections at the centre node of the drill holes. The specimen has been tested in bending only and for load ratios $R=F \min / F \max$ equal to -1 and to 0 , respectively. The specimen $\mathrm{B}$ has rigid connections between nodes on drill edges and a central node located on the drilling axis between the two parallel sides. Loads are applied on this central node. This specimen has been tested in bending and in tensile conditions for $R$ equal to -1 and -0.5 . Specimen $C$ loads are applied on a defined cylindrical area beginning at a $44 \mathrm{~mm}$ distance from the tube basis to the end of the tube. This area is a cylinder on which bending forces are applied according to a geometrical repartition. Torques are also applied on this superior tube area. This specimen has been tested in bending and in torsion for load ratio equal to -1 . The specimen $D$ has been tested in bending only and for load ratios $R$ equal to -0.2 ; -1 ; and -2 with stress relieved samples and for a load ratio equal to -1 for as welded samples.

\subsection{Hot spot location}

Cracks appear at weld seam toes in the thinner steel sheet for each specimen type.

In order to compare the stress states obtained with the two models within the cracking zone, the stress amplitude is evaluated over the curvilinear abscissa along the weld seam toe contour.
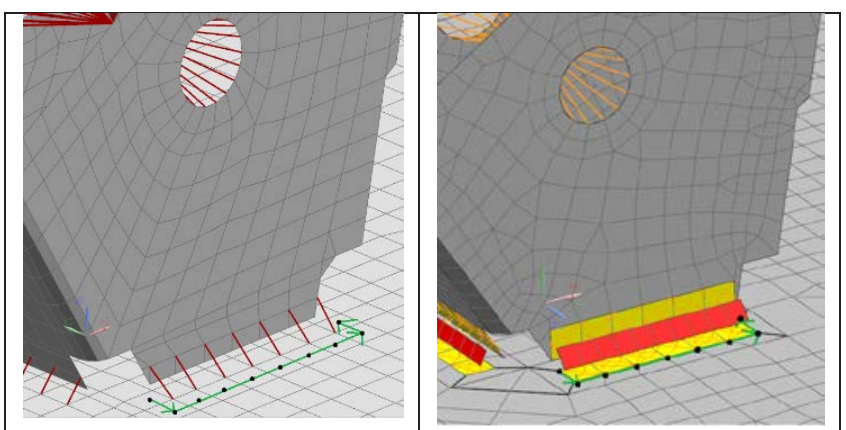

Fig. 7. Specimen B weld toe contour for both methods.

Based on model 1, the stress tensor is extracted at the weld toe contour at the corresponding element centroid. The maximum principal stress is used in case of tensile mode or bending mode tests. From maximum principal stress, the maximum stress amplitude can be evaluated considering minimum principal (out of plane) stress as null, so that: 


$$
\tau_{a}=\sigma_{I} / 2
$$

For the torsional load specimen, the in plane shear stress is used as $\tau_{a}$

$$
\tau_{a}=\left(\sigma_{I}-\sigma_{I I}\right) / 2
$$

Using the weld shell element in model 2, the structural stress is calculated thanks to the bending moment and the normal force perpendicular to the weld line. From nodal forces and moments at the node at the weld toe contour, the load densities are calculated by inverse matrixes of the element shape functions. This results in the line bending moment density $m_{x}$ and a line normal force $f_{y}$ (Fig.8.). The membrane normal stress $\sigma_{m}$ is calculated accordingly (4); and the bending moment leads to the bending normal stress $\sigma_{b}(5)$, where $t$ is the steel sheet thickness. The structural stress is the combination of the two normal stress components.

$$
\begin{gathered}
\sigma_{m}=f_{y} / t \\
\sigma_{b}=\left(6 * m_{x}\right) / t^{2}
\end{gathered}
$$

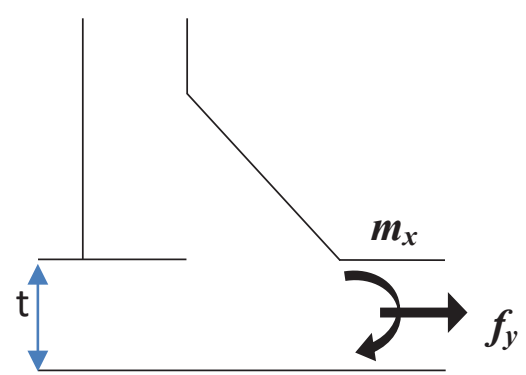

Fig. 8. Plate loads at the weed toe.

For the two methods, the corresponding design stress is plotted along the weld toe curvilinear abscissae, and both indicate the same distribution with the extremum value at the crack initiation location as shown in Fig.9., for specimen B, where hot spot is located at the seam weld termination.

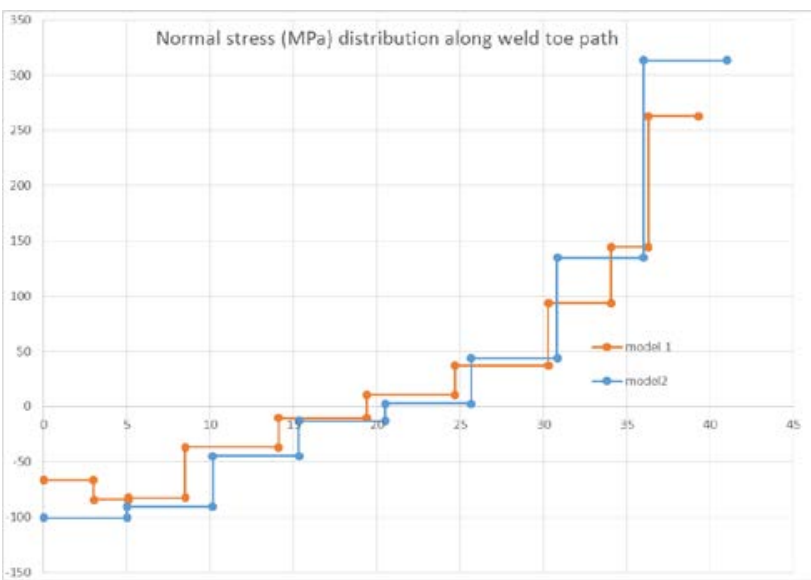

Fig. 9. Specimen B weld toe stress distribution.
The two methods give similar design stress value for specimens A and B. In the case of the torsional specimen $\mathrm{C}$, the shear stress at the weld side outer face of the shell element, a different stress value was observed. In model 1 , the calculated stress is much higher than in model 2. For a $1000 \mathrm{Nm}$ torque application the shear stress distributions over the weld toe contour are illustrated in Fig.10. In fact, due to cantilever rod connection, the torsion torque transmission generates nodal moments as illustrated in Fig.11. The longitudinal shear load transmission with the induced nodal moment generates a circumferential waving perturbation and in-plane opposite bending nodal moments at the shell element edge at the $1 \mathrm{D}$ connection side.

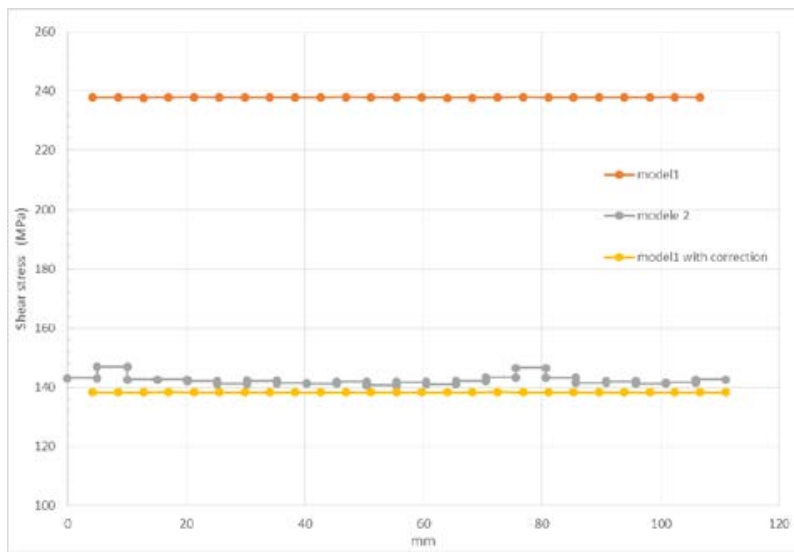

Fig. 10. $1000 \mathrm{Nm}$ torsion shear stress distribution specimen D.

This numerical effect may be vanished by extracting stress tensor over the shell element mid-surface. Comparing mid-surface shear results between the two models, the shear stress distributions are now similar as illustrated in stress value with correction in Fig. 10.

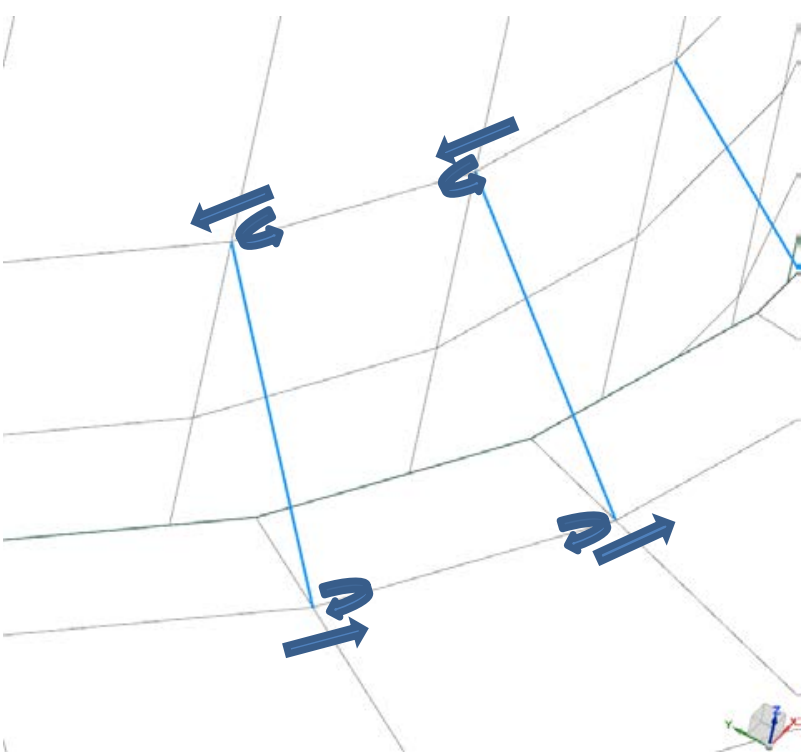

Fig. 11. $1000 \mathrm{Nm}$ torsion, force and moment nodal loads. 
This effect is reduced when using the model 2 where the $1 \mathrm{D}$ element node projection is only half of the plate thickness.

In order to compare the two models, the principal stress values are extracted at each specimen hot spot location. For bending and tensile load specimen, values are extracted on the top face of the element at the weld joint side and for torsional load, stress is extracted at the mid height shell surface. In order to compare the two models, the principal stress tensors at the hot spot location are evaluated and the values are given in Tab.1.

Tab.1. Principal stress tensors at hot spot location.

\begin{tabular}{|c|c|c|c|c|}
\hline & \multirow{2}{*}{\multicolumn{2}{|c|}{ load $100 \mathrm{daN}$}} & \multirow[b]{3}{*}{$\%$} \\
\hline & & & & \\
\hline & & model 1 & model 2 & \\
\hline \multirow{2}{*}{ A bending } & $\sigma \mathrm{I}$ & 310.0 & 290.56 & -6.27 \\
\hline & $\sigma \mathrm{II}$ & 180.0 & 152.1 & -15.5 \\
\hline \multirow{2}{*}{$\mathrm{B}$ bending } & $\sigma \mathrm{I}$ & 330.0 & 318.6 & -3.4 \\
\hline & $\sigma \mathrm{II}$ & 210.0 & 216.7 & 3.2 \\
\hline \multirow{2}{*}{ B tensile } & $\sigma \mathrm{I}$ & 273.0 & 230.0 & -15.7 \\
\hline & $\sigma \mathrm{II}$ & 210.0 & 180.8 & -13.9 \\
\hline \multirow{2}{*}{$\mathrm{C}$ bending } & $\sigma \mathrm{I}$ & 299.0 & 302.6 & 1.2 \\
\hline & $\sigma \mathrm{II}$ & 110.0 & 131.0 & 19.1 \\
\hline \multirow{2}{*}{$\mathrm{D}$ bending } & $\sigma \mathrm{I}$ & 98.0 & 112.0 & 14.3 \\
\hline & $\sigma \mathrm{II}$ & 23.0 & 20.0 & -13.0 \\
\hline
\end{tabular}

The first four load cases of table 1 show a consistent correlation between model 1 and model 2 results. Both models are able to represent the same multiaxial stress state at the weld toe within an overall scatter above $19 \%$. The historical proposal of Fayard is definitely proven effective for fatigue computation despite of the use of alternative seam weld FE model and solver, respectively. Even if it is the calibration of the model versus experimental results which most makes a design criterion effective, here knowing that the model is robust is a good point to note.

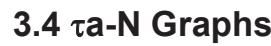

The $\tau_{a}-N$ graphs can be drawn, where $\tau_{a}$ is the maximal shear stress amplitude in the critical zone from the specimen and where $N$ is the cycle number after which one gauge located in those same critical zones during test phase has lost $30 \%$ of the initial signal.
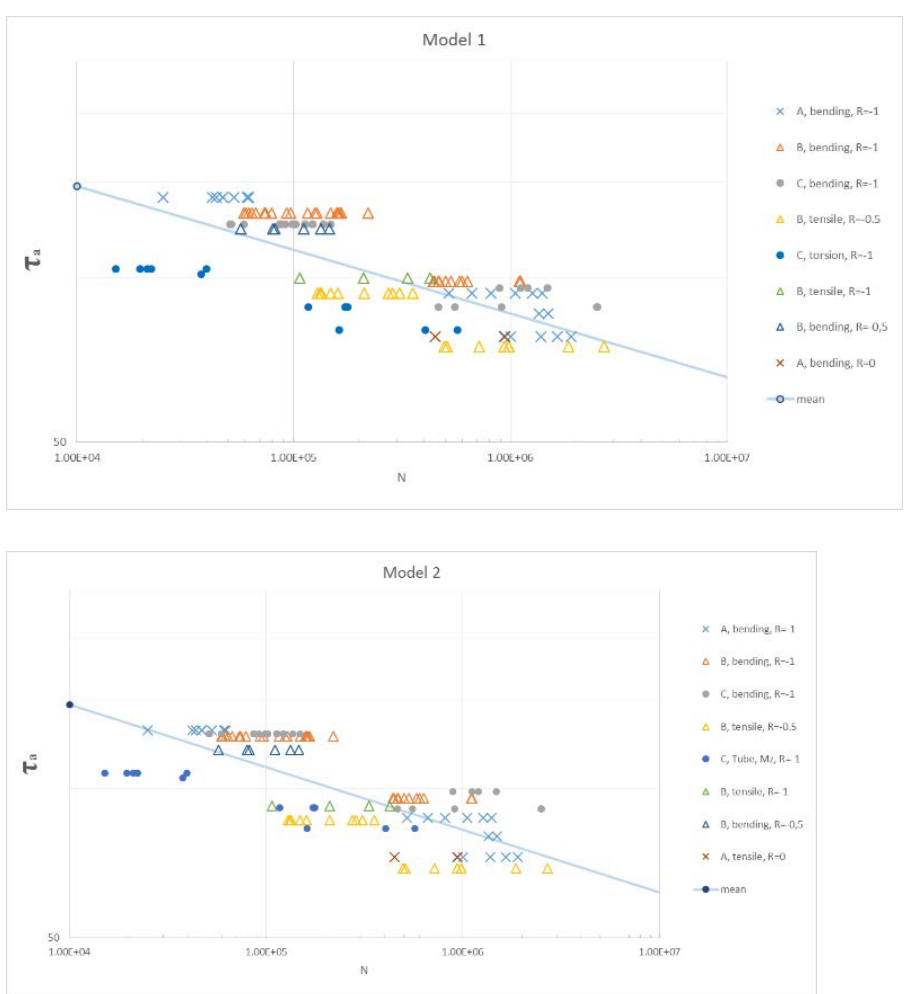

Fig. 12. $\tau_{\mathrm{a}}-\mathrm{N}$ for both models.

We notice that the range level between the two methods are quite similar. Average slopes also are similar: 8.55 for model 1 versus 7.94 for model 2. The two modelling methods lead to very similar results.

\subsection{S-N Graphs}

The aim of this section is to analyse the test results in terms of structural stress; only normal stress at the weld toe hot spot is taken into account or mid surface shear stress for the torsional specimen. For each specimen type, each solicitation type and each load ratio, an $\mathrm{S} / \mathrm{N}$ curve is plotted. Comparisons between specimens but also between different load ratios and solicitation type can be provided.

\subsubsection{Mean stress effect}

In order to study the mean stress influence, the data from specimen $\mathrm{D}$ are analysed because it offers the most diversified load ratio results; $\mathrm{R}=-0.2,-1,-2$ with relieved residual stress and $\mathrm{R}=-1$ without relieved residual stress. 


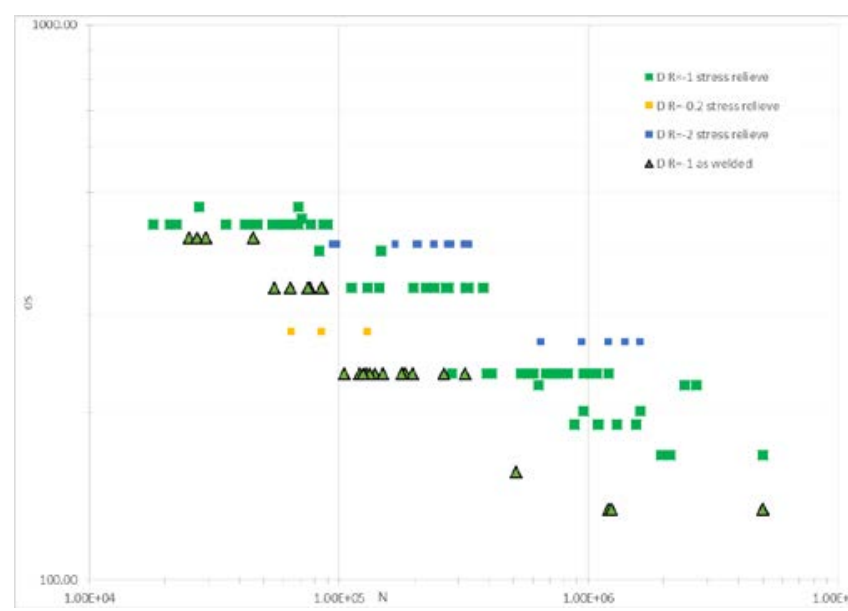

Fig. 13. $\sigma_{\mathrm{s}}-\mathrm{N}$ specimen $\mathrm{D}$.

The $\mathrm{S} / \mathrm{N}$ curve slope for no stress relieved specimen is $\mathrm{m}=4$, for stress relieved specimen $\mathrm{m}=5$. For each load ratio category an $\mathrm{S} / \mathrm{N}$ curve is established and a 2000000 cycles stress amplitude is evaluated and given in Tab.2.

Tab.2. 2 million cycles stress amplitude by load ratio.

\begin{tabular}{|c|c|c|c|}
\cline { 2 - 4 } \multicolumn{1}{c|}{} & load ratio & $\mathrm{m}$ & $\sigma_{\mathrm{s}}$ \\
\hline stress relieved & $\mathrm{R}=-1$ & 5 & 201.64 \\
\hline stress relieved & $\mathrm{R}=-2$ & 5 & 249.74 \\
\hline stress relieved & $\mathrm{R}=-0,2$ & 5 & 151.58 \\
\hline as welded & $\mathrm{R}=-1$ & 4 & 134.39 \\
\hline
\end{tabular}

The mean stress influence factors from the test results are compared to IIW recommendations [8]. For stress relieved specimen, the mean stress correction factor is $0.4 \mathrm{R}+1.2$ when $\mathrm{R}$ varies from 0.5 to -1 . The test result for $\mathrm{R}=-1$ is taken as reference, the correction is applied and it fits the test result when $\mathrm{R}$ equals to -0.2 , see Fig. 14.

IIW correction limits mean stress effect factor to 1.6 when $\mathrm{R}$ reaches-1, but tests show that fatigue mean stress influence is still present for higher compressive mean stress when $\mathrm{R}=-2$.

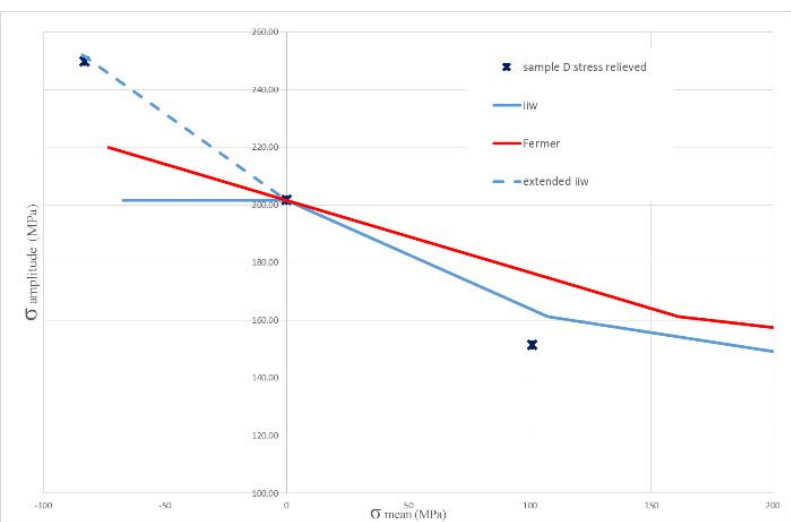

Fig. 14. Mean stress effect corrections and specimen D results.
In [6], Fermer established a correction method for load ratios for two $\mathrm{R}$ domains; $\mathrm{R}$ being negative or $\mathrm{R}$ being positive, with no specific $\mathrm{R}$ value limits. This mean stress influence is illustrated in Fig. 12 and it does not have enough effect to fit the test results.

A proposal is to extend IIW recommendation $\mathrm{R}$ correction formula down to $\mathrm{R}=-2$. The resulting correction does fit with results, and the factor related to $\mathrm{R}=0.2$ to $\mathrm{R}=-2$ is 1.56 for a test result factor equals to 1.65 .

For $\mathrm{R}=-1$, the stress relieved effect is quantified by a factor 1.3 for thin metal sheet assembly and 1.6 for 3D thick component in [8], the test leads to a factor equals to 1.56 , which is consistent.

When considering IIW mean stress correction the estimated structural stress amplitude for 2 million cycles would be for $\mathrm{R}=0.5,126 \mathrm{MPa}$.

\subsubsection{IIW structural stress comparison}

For structural stress, the IIW guideline, [9], proposes FAT90 as design $\mathrm{S} / \mathrm{N}$ curve for load carrying fillet weld and FAT100 for no load carrying fillet welds. Those FAT values correspond to a stress range limit ( $\max -\min$ ) for 2 million cycles, a load ratio $\mathrm{R}=-0.5$ and a survival probability of $97.5 \%$ and a slope $m=3$.

To compare with the test results, mean stress effect correction for $\mathrm{R}=0.5$ is performed and corrected structural stress results are displayed in Fig. 15.

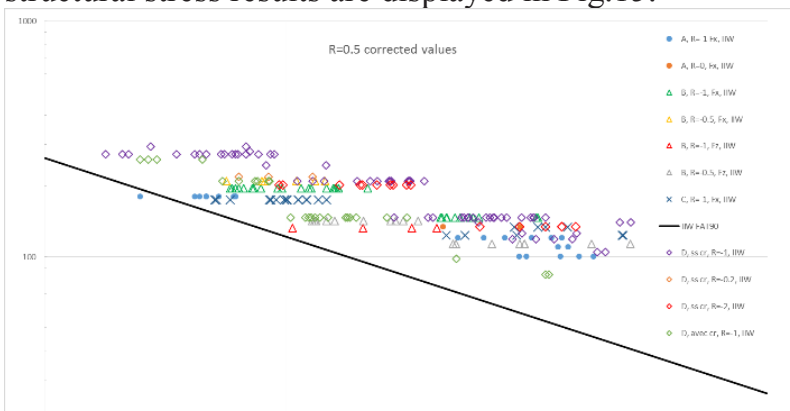

Fig. 15. Structural stress amplitude vs N.

Test results show much higher stress limits than IIW design values. For low cycle number, FAT90 is not conservative. In case of low strength steel, as mentioned in IIW recommendations, the design curves are appropriate on the condition that the stress range should be within the limits of the elastic properties of the material. The range of the design values of the stress range shall not exceed 1.5 times the yield strength.

High value for high cycle number is dedicated to the automotive thin sheet assembly, and the associated weld quality and may not be transposed to other applications. At the hot spot locations, the metal sheet thickness is either 2 or $2.5 \mathrm{~mm}$, the thin walled structure has a thickness improve effect which might be investigated. 


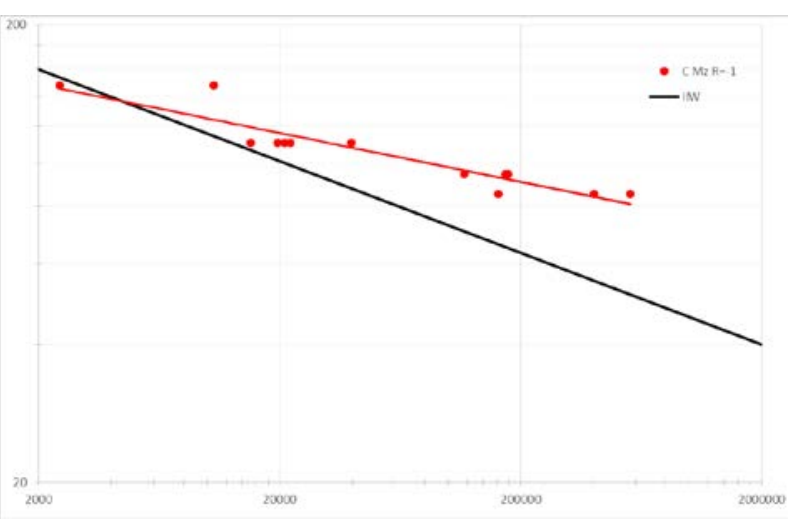

Fig 16. Shear stress amplitude $\tau a-N$.

For shear stress, IIW S/N curve is FAT80 with $m=5$ and it is given for nominal stress for fillet weld in [8]. Torsion test shear stress mid-plane values are given in Fig. 16. The fitted S-N curve slope is nearly 9. IIW design S-N curve is also conservative as long as the number of cycles is higher than 100000 cycles.

\section{Conclusions}

For fillet weld fatigue assessment, Fayard model (model 1) has been validated on the basis of an intensive testing campaign using four welded specimen configurations.

A recent fillet weld shell element model (model 2) has been proposed and validated for weld root fatigue assessment using structural stress approach. The aim of the work has been to verify its use for automotive weld assembly fatigue assessment.

Based on the four specimens, the comparison is performed by generating the stress density distribution at the weld toe and the hot spot location is correlated.

In the case of tensile and bending test configurations, the principal stress components calculation show a consistent correlation between model 1 and model 2 results. Both models are able to represent the same multiaxial stress state at the weld toe within an overall scatter of $19 \%$.

The calculated fatigue shear stress Woehler curves give very similar distribution for the two modelling techniques. The historical proposal of Fayard is definitely proven effective for fatigue computation despite of the use of alternative seam weld FE model and solver, respectively. Even if it is the calibration of the model versus experimental results which most makes a design criterion effective, here knowing that the model is robust is a good point to note. Conversely, the last configuration relative to torsion load specimen highlights a major difference indeed. This is due to two different shortcomings already detailed in $\$ 3.3$, i.e. the shear stress distribution within the tubular member thickness (Fig.11) and a circumferential waving perturbation at the two sides of the weld toe connection, respectively. Thus, in this very particular load case, the historical proposal of Fayard suffers from a relevant over-estimation of the stress state, mainly driven by a low-level numerical instability of the FE model. Actually, at present it would be an easy and hasty judgment to simply announce that the Fayard framework is non-conservative. Further impact analysis is expected before stating a definite conclusion. In this case, the correlation of the two modelling approaches is obtained by using a localnominal shear stress value at the connected plate from either the element mid-plane stress tensor or by the shear nodal force transformation.

The analysis of the tests result using the structural stress method leads to several issues. The mean stress influence factor proposed by IIW recommendation may be extended for high compressive mean stress with a continuously benefit effect. Test results are compared to IIW design S-N curves which are very conservative and not appropriate for automotive applications. This is due to the use of specific steel grades in thin steel sheet assembly with high quality process.

1. J.L. Fayard, "Dimensionnement à la fatigue polycyclique de structures soudées", Thèse Ecole Polytechnique (1996)

2. K Dang Van, A Bignonnet, J.L. Fayard, "Assessment of welded structures by a structural multiaxial fatigue approach", Biaxial/Multiaxial Fatigue and Fracture, (Elsevier Science Ltd. And ESIS. Publication 31, 2003)

3. W. Fricke, "IIW guideline for the assessment of weld root fatigue". Weld World 57(6):753-791, 2013 doi:10.1007/s40194-013-0066-y

4. D. Turlier,P. Klein, F Bérard, "Seam Sim" method for seam weld structural assessment within a structure FEA". Proc. Int. Conf. AWST 2010, ( GEDIK Education foundation, Istanbul, pp 651-658 2010)

5. D. Turlier, P. Klein, F. Bérard, "FEA shell element model for enhanced structural stress analysis of seam welds", Weld World (2014) 58: 511. doi:10.1007/s40194-014-0134-y

6. M. Fermér, M. Andreasson, B. Frodin, "Fatigue life prediction of MAG-welded thin-sheet structures", (SAE Technical Paper 982311, 1998).

7. M. Fermér, H . Svensson, "Industrial experiences of FE-based fatigue life predictions of welded automotive structures", (Blackwell Science Ltd. Fatigue Fract Engng Mater Struct 24, 489-500, 2001)

8. A. Hobbacher, "Recommendations for Fatigue Design of Welded Joints and Components", $2^{\text {nd }}$ edition, Springer International Publishing, 2016. doi: 10.1007/978-3-319-23757-2

9. E. Niemi, W. Fricke, S.J. Maddox, Structural HotSpot Stress Approach to Fatigue Analysis of Welded Components - Designer's Guide, Second Edition, Springer Nature Singapore Pte Ltd. 2018. doi:10.1007/978-981-10-5568-3 